Fecha de recepción: febrero 2010 Fecha de aceptación: agosto 2010 Versión final: marzo 2011

\section{Política 2.0 y la comunicación en tiempos modernos}

Lucas Lanza y Natalia Fidel ${ }^{(*)}$

\begin{abstract}
Resumen: Este artículo analiza cómo los nuevos medios -internet y las redes sociales- han cambiado el ecosistema de información política, con nuevos canales e información fluyendo con mayor rapidez, con un consumidor que también ahora es generador de noticias: el nuevo prosumidor. Esta convergencia de medios tradicionales y nuevos, demanda nuevas capacidades cognitivas por parte de los usuarios. Y nuevas destrezas por parte de los candidatos políticos, que necesitan intervenir con mensajes más segmentados y con capacidad para administrar la conversación. También, se analizan casos emblemáticos, como la campaña de Barack Obama como ícono de la comunicación política 2.0, y se describen y contextualizan escenarios y presupuestos, según datos del Observatorio Permanente de Política 2.0, del Instituto Política \& Democracia de la Sociedad de la Información para las Américas.
\end{abstract}

Palabras claves: comunicación digital - comunicación estratégica - Comunicación Política - comunicadores - Dircom - nuevas tecnologías - política 2.0 - públicos - público gobierno - redes sociales - Relaciones Públicas - social media - Twitter.

[Resúmenes en inglés y portugués y currículum en las páginas 62-63]

\title{
Introducción
}

Los nuevos medios de información y comunicación -como internet y las redes sociales- han cambiado el ecosistema de información política. Hoy existen nuevos canales, más información y de diferente índole, porque ésta fluye con mayor rapidez y porque el consumidor también es generador de noticias, en su nuevo papel de prosumidor: periodistas ciudadanos, inteligencia colectiva que se auto-organiza para manifestarse o descubrir operaciones tendientes a manipular la opinión pública o individuos que saltean las instituciones tradicionales para des-mediatizar su conexión directa con los votantes son algunos de los efectos que producen.

En esta convergencia entre los medios tradicionales y los nuevos medios, hay una demanda de nuevas capacidades cognitivas por parte de los usuarios de información. Las nuevas generaciones aprehenden rápidamente los nuevos códigos de relacionamiento, porque este universo no les es novedoso, habiendo nacido o crecido inmersos en él. Son los llamados 'nativos digitales' quienes, elección tras elección, y por una obvia razón generacional, van ganando mayor volumen entre el electorado año tras año.

Esto implica mayores y nuevos esfuerzos por parte de los candidatos políticos: los flujos de información política se multiplican, porque las esferas públicas también lo hacen: la televisión, 
la radio y los diarios. Ahora ya no alcanzan la vertiginosidad de los foros, blogs y redes sociales que proporciona internet, canales que se alimentan de la voz y la acción de todo y de todos (políticos y ciudadanos). Es necesario entonces intervenir con información, mensajes más segmentados y con capacidad para administrar la conversación. En los Estados Unidos, internet es tan importante como los periódicos y tiene casi el doble de importancia que la radio a la hora de informarse o involucrarse en política. El fenómeno de Barack Obama es la evidencia que prueba que una campaña organizada bajo el concepto 2.0, puede revolucionar la manera de hacer política y generar adhesiones. También, en otras partes del mundo, como Alemania e incluso América Latina, el concepto 2.0 va experimentando escenas primarias donde queda en evidencia el impacto de estas nuevas herramientas de comunicación

En Argentina aún no se han experimentado acciones de impacto en esta materia a pesar de que nuestro país se encuentra en los primeros puestos de conectividad. Posiblemente, la reciente reforma política y la ley de medios de 2009 que cambian las instancias de contienda política y de comunicación, brinden el empujón necesario para que en la campaña presidencial de 2011 se vivan las primeras elecciones 2.0 en Argentina.

\section{Nuevos medios, nuevos electorados}

La propuesta es pensar cómo era el contexto mediático que tuvieron durante su niñez y juventud de quienes hoy ocupan el poder y los espacios políticos más importantes del país durante su niñez y juventud. La primera transmisión de televisión en Argentina se realizó el 17 de octubre de 1951. Se transmitió desde la Plaza de Mayo mientras que Juan Domingo Perón le hablaba a una multitud el día de la Lealtad Peronista. Solamente treinta costosos televisores recibían la señal desde la antena montada en el edificio del Ministerio de Obras Públicas. En ese entonces, la actual Presidente de la Nación, Cristina Fernández de Kirchner, tenía apenas 2 años.

A su vez, en 1978 la televisión argentina realizó su primera transmisión a color durante el mundial de fútbol que se llevaba a cabo en nuestro país. Ningún hogar argentino poseía un receptor que permitiera disfrutar de la cancha verde. Solamente algunos televidentes en el exterior pudieron recibirla de esta manera. Es decir que 27 años fueron los que separaron la transmisión a color de la blanco y negro en Argentina.

Por su parte, la magnitud y la velocidad de los cambios producidos en los medios de comunicación en los últimos años ha sido exponencial y esto se evidencia en el hecho que mientras que a la radio le llevó 38 años alcanzar una audiencia de 50 millones de oyentes y la televisión tardó 14 años para lograr ese número de televidentes, internet sólo necesitó 4 años (Mediosfera, s/f). Por otra parte, aplicaciones como Facebook o Twitter superaron ampliamente esas audiencias a pocos meses de su lanzamiento.

Estos cambios exponenciales en la comunicación han definido un nuevo ecosistema de medios. Al mismo tiempo, las capacidades cognitivas de las audiencias se modificaron, y los productos de comunicación han tendido a complejizarse para poder retenerlas. Se produce entonces un nuevo mix de medios donde convergen los medios tradicionales con las nuevas tecnologías, como los videos juegos en línea, los mensajes de texto, las redes sociales, los blogs, mensajes instantáneos, microblogging y multimedialidad e interactividad ubicua en la palma de nuestras 
manos a través de los smartphones. Este consumo y demanda de medios ha provocado un cambio en la oferta de los productos comunicacionales.

Si se analizan las series televisivas, tal como lo hace Alejandro Piscitelli en sus conferencias y en su último libro Nativos Digitales (2009), se observa cómo la necesidad de atraer a una nueva audiencia multitasking ha generado un nuevo formato narrativo deseoso de retener la atención de un espectador bombardeado de estímulos y acostumbrado a administrar una dosis mayor y más compleja de información. Así, mientras las series televisivas de los años '70 u ' 80 s como Bonanza, Chip o, Starsky y Hutch tenían estructuras narrativas muy simples, las nuevas tiras de HBO o de FOX como 24, Lost o Dr. House, entre otras, requieren de la audiencia una atención y un esfuerzo cognitivo que permita conectar una veintena de personajes principales que entran y salen de la escena entrelazados en diferentes conflictos e hilos narrativos a lo largo de escasos 40 o 50 minutos de duración de cada capítulo.

Naturalmente las generaciones más jóvenes son las que más rápidamente se adaptan a la nueva oferta de medios y productos de comunicación. Quienes se desarrollaron y vivieron durante largos períodos con los medios tradicionales, posiblemente tarden más en aprehender las nuevas herramientas. Pero sin lugar a dudas quienes están naciendo durante la era de la información, los llamados Millennials o Generación $Y$, son nativos de un mundo digital que no comprenden la vida de otro modo que no sea viviendo hiperconectados.

Estas nuevas audiencias, con nuevas dietas cognitivas conforman a su vez nuevos electorados. Las nuevas generaciones están ganando volumen, elección tras elección, en el porcentaje de la población que vota. Sus hábitos de consumo y lenguaje deben ser tenidos en cuenta por los políticos que quieren acercarse, dialogar con ellos y obtener su confianza y su voto. Según un estudio de Pew Internet \& American Life Project sobre el uso de internet en las elecciones norteamericanas de 2008, el 74\% de los usuarios de la web -que representan el 55\% de la población adulta- utilizó Internet para involucrarse en política o buscar información acerca de la elección. Otros datos que se desprenden del estudio indican que:

- Uno de cada cinco usuarios de internet (18\%) publicó algún comentario o participó con su opinión en periódicos online o blogs vinculados al debate político.

- El 45\% de los usuarios de internet accedió online para ver algún video relacionado con la campaña o alguno de sus candidatos.

- Uno de cada tres usuarios de internet reenvió o compartió información y contenidos sobre política con otros usuarios.

- El 83\% de los usuarios jóvenes entre 18 y 24 años poseen un perfil en alguna red social. Dos terceras partes de ellos tomaron parte en alguna discusión o se involucraron en alguna actividad política a través de esos sitios.

- Por la composición demográfica de los votantes, quienes seguían a Obama tenían más compromiso que los seguidores a McCain en la participación online (donar para la campaña, participar como voluntarios, dar a conocer sus opiniones, suscribirse a actividades) (2008). 
En síntesis, este estudio demuestra la importancia que ha adquirido internet dentro del conjunto de medios que ofrece información política, al alcanzar en nivel de penetración y consumo a los periódicos y casi duplicar a la radio como fuente de información relativa a las elecciones que se llevaron a cabo en los Estados Unidos. Este dato aumenta en la población de jóvenes adultos. Además, al compararse el consumo de información de los medios tradicionales como la televisión con el de los nuevos medios, este último se considera más profundo y participativo: si bien el 70\% eligió a la TV como un lugar de información política, el mismo representa un canal pasivo cuya única acción posible es la de encender y mirar la pantalla.

\section{La diferencia entre estar o ser 2.0}

John F. Kennedy es recordado como 'el candidato de la televisión' a partir de los debates protagonizados con Richard Nixon en 1960. Por su parte, Barack Obama será recordado como el ícono 2.0 por haber obtenido significativos resultados a partir del uso de nuevos medios durante su campaña hacia la presidencia durante el año 2008.

Acompañado por un brillante equipo dirigido por David Plouffe, Barack Obama puso en marcha un liderazgo 2.0 tras reconocer y comprender el nuevo contexto de comunicación y las demandas de contenidos y espacios participativos de su electorado.

La campaña del actual presidente de los Estados Unidos no solamente estuvo en el espacio 2.0, sino que la estrategia fue ser 2.0. Mientras otros candidatos construían sus websites, posteaban sus videos en YouTube y creaban sus perfiles en redes sociales como Facebook o MySpace, el equipo demócrata puso en marcha un definido plan de acción que unía cuidadosamente las actividades de cada área del organigrama de campaña para acercarse a sus electores, involucrándolos no sólo con la información que ellos querían escuchar sino con actividades mucho más comprometidas, como registrarse en el equipo de voluntarios o aportar fondos para el financiamiento de la campaña.

El plan no se basó en la puesta en marcha de nuevas tecnologías. El éxito radicó en utilizarlas con sentido. Se trabajó motorizando actividades y difundiendo contenidos de manera segmentada, según la geografía, temática y demografía. A través de diferentes aplicaciones como my.barackobama.com o el programa neighbor to neighbor canvassing, se pudo distribuir el trabajo de la gestión de las actividades de campaña en subgrupos de militantes y referentes en cada estado, lo que permitió administrar un mayor volumen de contactos.

Los resultados fueron evidentes. Se recaudaron más de 618 millones de dólares (más del doble que cualquier otro candidato en la historia de los Estados Unidos), con contribuciones de más de 3.1 millones de personas en donaciones que en promedio no superaban los 86 dólares, según la Federal Election Comision de los Estados Unidos (2009). El ciudadano norteamericano se convirtió así en partícipe del cambio, sintió el proyecto político como propio y se comprometió con el mismo. 


\section{Nuevo ecosistema de información política}

Más allá de la esfera política, lo cierto es que cada día más profesionales, oficinistas, administrativos, empleados estatales, estudiantes, incluso amas de casa, pasan más tiempo online. El incremento exponencial de accesos de banda ancha en hogares -ya había sucedido en empresas- el aumento de líneas celulares, de smartphones y accesos a internet $3 \mathrm{G}$ modifican sustancialmente la forma del consumo de información diario en segmentos cada vez más masivos de la población.

Aquellos grupos más informados, más afines al consumo de noticias o información relativa a la actualidad, la economía o la política -posiblemente segmentos más influyentes sobre otros grupos- experimentan desde hace apenas pocos meses atrás un nuevo flujo de circulación de información y noticias. Esto ocurre en mayor medida en los Estados Unidos -a quienes se los denomina influentials- pero con la misma tendencia en Argentina e incluso en países con menos densidad de conectividad.

¿Cómo era el circuito de las noticias hace 50 años? O más específicamente: ¿cómo era el flujo de noticias de actualidad hace 20 años atrás? Comparar ese escenario con la actualidad puede ser un ejercicio interesante que no se pretende agotar en este articulo. Sin embargo, para los fines de este análisis, la idea es visualizar de modo más evidente los cambios en la comunicación que generan los nuevos flujos de información política.

En 1989 la internet era apenas un embrión con respecto a las utilidades que se conocen en la actualidad. Los grandes avances de esa época resultaron fundamentales para el desarrollo posterior, pero el concepto de internet como medio de comunicación masivo y social era por entonces inexistente. Un dato interesante a tener en cuenta: Timothy John Berners-Lee, físico británico de la Universidad de Oxford implementó por primera vez en 1989 el hipertexto (HTML), lo que hoy conocemos con WWW sin mucho éxito. No fue hasta 1993 que con el lanzamiento del navegador MOSAIC, co-creado por Marc Andreessen -fundador de Netscapeque se alcanzó un desarrollo de interfase capaz de navegar hipertextualmente en un entorno gráfico. El protocolo de comunicación, el lenguaje de programación y el navegador hicieron de la $w w w$ la Killer App que revolucionó a internet y la trasladó de los ámbitos académicos y científicos al consumo masivo.

Sin internet, los medios masivos como la prensa gráfica, la radio y la televisión acaparaban la mayoría -sino la totalidad- de la escena de la comunicación política. Los actos masivos eran incluso -y son en la actualidad- meros acontecimientos producidos para ser mediatizados.

Hoy las aplicaciones y productos online irrumpen y modifican el flujo informativo, impactando en la velocidad, distribución y en el contenido mismo que llega a la audiencia. La propuesta es imaginar entonces una crónica hipotética y simbólica de circulación de noticia o información para ilustrar este punto:

\section{La crónica}

Ciudad de Buenos Aires, Jueves,11:34 AM. Muy pocos minutos de terminada una reservada reunión entre un conjunto de funcionarios del Poder Ejecutivo con legisladores de una oposición dispuesta a dialogar, se twittea desde el perfil de un Ministro: "Acordaron. Apoyarán la ley". Los opositores visitantes aún no alcanzaron a subir a los autos para partir hacia sus respectivos despachos. Apenas logran comunicarse telefónicamente con sus asesores para empezar a relatar 
los detalles que formarán parte del comunicado oficial. Bloggers, algunos periodistas, militantes e incluso enemigos políticos son parte de los cientos de followers que conocen casi inmediatamente la noticia. Muchos de ellos la re-twittean para sus propios seguidores. Autores de blogs políticos y de actualidad no lo hacen. Prefieren anunciarlo como primicia en su portal. Los periodistas de medios nativos online con menos rigurosidad le dan más cuerpo al dato y con la venia atenta del editor lo anuncian en su sección de 'último momento'.

11:50 AM. Ya no son sólo los cientos de seguidores del Ministro que conocen la primicia. La red de individuos conectados por intereses similares multiplica exponencialmente la información antes de que se empiece a redactar el 'comunicado oficial' de cada parte. En varios perfiles de Facebook se disemina la novedad como un virus. Ya son muchos más los que se preguntan de qué se trata.

Quienes se encontraban trabajando en su oficina frente a su computadora o revisando su Blackberry mientras viajaban de un lado al otro de la ciudad quieren saber más y visitan las versiones online de los principales diarios nacionales para confirmar el rumor. Nada aún... Ya sea por una razón estructural de sus redacciones, por el profesionalismo que impone el chequeo de la información o por ambas cosas, la versión online del diario de cada mañana aún no titula la novedad. El comunicado oficial no aparece. Periodistas radiales con su programa en vivo dan a conocer la primicia. El monitor frente al micrófono recibe correos electrónicos de oyentes que preguntan sobre el tema. Sus productores deciden comunicarse con los protagonistas. No hay respuesta hasta que se cumpla con el proceso interno y se defina el mensaje que comunicarán los voceros designados. Claro que a esa altura el comunicado deberá apurarse y salir de inmediato. El mensaje posiblemente tenga que modificarse según se había previsto originalmente, ya que el rumor ha cambiado el efecto que se tenía planeado y ya existe una versión de la noticia con puntos para aclarar o enfatizar.

13:30 PM. Finalmente los diarios lo publican en sus portadas online. Aquellos navegantes que tienen más interés en profundizar la información 'googlean' el nombre de los principales actores. Visitan los perfiles que se publican en Wikipedia, en sus páginas personales o leen la información (no del todo confiable y frecuentemente negativa) en blogs o portales de agencias de noticias, inteligencia o producto de operaciones anteriores.

Los programas periodísticos de cable sacan al aire entrevistas telefónicas mientras envían sus móviles a la búsqueda de más testimonios, que luego repiten cada media hora en sus titulares hasta después del prime time donde los programas de análisis periodísticos buscarán que la confrontación de opiniones entre los invitados determine los titulares de los diarios del próximo día. Los asesores de prensa de cada parte se esfuerzan en sacar sus comunicados intentando menciones en los diarios online, aunque su modelo tradicional sea el de llegar antes de las 18 hs a las redacciones o agencias de noticias atentos a los titulares del próximo día. A esa altura, más de un activo usuario de la red crea grupos de debate en Facebook. Los hay a favor o en contra sumando a cada momento nuevos fans quienes, sin ningún tipo de filtro, se despachan con sus ideas y opiniones.

Al día siguiente los diarios relatarán una noticia que ya resulta vieja, y claro está, harán mención al 
comentario inmediato del Ministro en su red de Twitter. El valor agregado que ofrecen es la editorialización y la opinión de analistas y referentes que muestran sus puntos de vista. Las opiniones de los lectores online se vuelcan de a cientos modificando muchas veces el contenido de la noticia. Militantes, fervientes seguidores opinan a favor o en contra intentando influir en el debate.

El ciclo continúa. Se transforma en una secuencia interminable de temas. En un flujo que modifica la noticia a cada instante, haciéndola rápidamente perecedera. Incorporando a la vez un conjunto de nuevas audiencias que dejan de estar a merced de la información concentrada en pocos canales y que se vuelve en parte conocedora calificada de detalles producto de su instantánea investigación en la red.

Pueden ocurrir infinidad de sucesos particulares que modifiquen el rumbo o el volumen de la información. Pero con este simple relato ficticio, se ha podido visualizar la velocidad y multiplicidad de participantes por donde circula la comunicación, lo cual está inherentemente asociado a una convergencia de medios fusionada por las nuevas tecnologías de información y comunicación.

La direccionalidad de la información ha cambiado, y en su nuevo recorrido genera múltiples espacios de intervención, a la vez que modifica los tiempos de aquel mensaje único y masivo tradicional.

\section{Escenas primarias de la política 2.0}

Volviendo a crónicas más reales, el nacimiento y la evolución de la 'política 2.0' tiene su propio relato. Fue surgiendo a partir de escenas primarias: momentos fundacionales que llamaron la atención y produjeron un cambio en el escenario tradicional de la comunicación política. Muchos de ellos ocurrieron durante la campaña electoral en los Estados Unidos en 2004, en donde ya existía una importante masa crítica conectada a Internet de alta velocidad con apenas algunas primeras aplicaciones de conversación o interacción entre los usuarios. Internet no es la única protagonista de este cambio. La interacción entre usuarios vía mensajes de texto también forma parte de la política 2.0, o podríamos llamarla 2.1 por ser móvil.

'Hoy 13-M a las 18 horas sede PP C/Génova 13. Sin partidos. Silencio. Por la verdad. ¡Pásalo!', recibían por SMS celulares madrileños. Pocas horas antes, a las 7:37 de ese 11 de marzo de 2004, varias bombas habían estallado en las cercanías de la Estación de Atocha en Madrid causando más de 190 muertes. Faltaban apenas 3 días para las elecciones generales presidenciales. Después del hecho, fuentes oficiales del gobierno de José María Aznar adjudicaron al grupo separatista ETA el salvaje atentado y los medios de comunicación se hicieron eco de la versión oficial. El diario El País publicó una edición especial con un gran titular en su portada: 'Matanza de ETA en Madrid' (11 de marzo, edición vespertina). Poco tiempo después un comunicado de ETA desmintió las acusaciones y sugirió que el atentado había sido realizado por células terroristas islámicas en respuesta al apoyo de Aznar al Presidente de los Estados Unidos en la invasión a Irak.

La falta de transparencia y la manipulación de la información del gobierno a través de los medios de comunicación propiciaron a la ciudadanía a manifestarse públicamente apenas 12 horas antes de los comicios y en plena veda electoral. Así, una convocatoria organizada a través de SMS reunió a miles de ciudadanos frente a la sede del Partido Popular. El candidato de Aznar, 
Mariano Rajoy perdió la elección ante el PSOE, encabezado por José Luis Zapatero.

Unos meses después, en septiembre de 2004 en los Estados Unidos, una noticia sacudió la campaña electoral en la que George W. Bush se jugaba su reelección frente al candidato demócrata John Kerry, en lo que luego se conoció como el Memogate.

Durante una emisión del programa 60 minutos, conducida por Dan Rather en horario central, la cadena CBS difundió documentos que referían a una supuesta desobediencia de George W. Bush durante el servicio militar en su juventud. Una noticia de esas características resultaba imperdonable para un candidato republicano. Al paso de los días la noticia comenzaba a tener efecto en las encuestas. Pero ante la preocupación de asesores y estrategas de campaña, foros y blogs en internet comenzaron a cuestionar la validez de los documentos, demostrando que parte del texto del memo en cuestión- un superíndice que precedía una fecha- jamás hubiese podido imprimirse con máquinas de escribir de aquella época, en la que supuestamente había sido escrito ese documento. Redes de apoyo al candidato Bush se organizaron a través de Internet y llamaron a un concurso para premiar a aquel individuo que encontrara una máquina de escribir antigua capaz de tipear ese caracter. El resultado: un documento apócrifo. La legitimidad y credibilidad de la cadena $C B S$ fue puesta en jaque y varios directivos debieron renunciar. Más recientemente, a sólo horas de la Convención Nacional Demócrata, el Senador Barack Obama, candidato presidencial de ese partido, anunció el 23 de agosto de 2008 que había elegido a su acompañante de fórmula. 'Barack ha elegido al senador Joe Biden como nuestro candidato a vicepresidente, pasa el mensaje!', recibían simultáneamente más de 3 millones de personas vía SMS y otro tanto a través de correos electrónicos en todo el mundo. Todos teníamos la primicia de primera fuente.

Algo similar al desencadenante de la noticia en esta crónica, sucedió en Alemania en mayo de 2009. Quienes integraban la red de Twitter de Julia Kloeckner, miembro del Parlamento alemán, se enteraron con 15 minutos de antelación sobre la elección del nuevo presidente, Horst Köhler. Los medios de comunicación esperaban la noticia por parte del representante del Bundestag, pero más de un congresal salteó el formalismo y filtró la noticia desde su banca en tiempo real, debiendo salir a disculparse por el timming prematuro del mensaje.

El atentado en Madrid, el Memogate de 2004, el anuncio del candidato a vicepresidente de Barack Obama y el twitteo anterior al anuncio formal del presidente electo de Alemania son anécdotas cortas pero altamente elocuentes. Se han constituido en acontecimientos primarios de un nuevo escenario de comunicación mediada por las nuevas tecnologías y sus respectivos hábitos de uso.

Flash-Mobs: la capacidad de organización horizontal de ciudadanos para manifestarse en el caso de Atocha y modificar el rumbo de una elección.

Crowdsourcing: la inteligencia colectiva que se organiza para resolver un problema propuesto y pone en jaque la veracidad de un medio tradicional en el Memogate. La comunicación masiva directa, el bypass de Obama y la legisladora alemana a los medios tradicionales para llegar con la noticia a la ciudadanía son acontecimientos simbólicos que nos obligan a reflexionar sobre las nuevas formas de comunicación.

En los últimos tiempos, tanto la Argentina como otros países latinoamericanos han enfrentado diversas situaciones y razones para abordar este desafío de buscar otras maneras de difundir su mensaje político sin pasar por los medios de comunicación tradicionales. En Argentina, la Ley de Radiodifusión aprobada recientemente en el Congreso Nacional y el proyecto de Ley de 
Democratización de la Representación Política, Equidad y Transparencia Electoral impulsado por el Poder Ejecutivo modificarán de seguro las reglas de juego, obligando a repensar la comunicación política. Al limitar el uso de la televisión para campaña política, queda claro que se abre el camino para el uso proselitista de los nuevos medios.

Se puede vislumbrar un nuevo mapa de medios más fragmentado, con una fuerte presencia de canales y contenidos oficiales producto de la regulación estatal establecida por la nueva Ley de Medios. Además, la tácita prohibición de destinar aportes privados a pautas radiales y televisivas de los candidatos y partidos políticos durante las campañas electorales que propone la Reforma Política invita a crear nuevas alternativas para convencer a los electorados. Esta es la tendencia que se asoma de cara a las elecciones presidenciales de 2011: un uso mucho más intensivo -y esperamos de mayor calidad- de los nuevos medios de información y comunicación en política.

\section{La política 2.0 en Argentina}

El observatorio Permanente de Política 2.0, del Instituto Política \& Democracia de la Sociedad de la Información para las Américas viene realizando desde el año 2007 un monitoreo cualicuantitativo del desarrollo de campañas, candidatos y políticos en la web. Si bien Argentina es uno de los líderes de la región en términos de conectividad y acceso a internet, todavía no se ha internalizado la cultura del '2.0' como un espacio para dialogar con la ciudadanía, hacer más participativos y colaborativos los procesos de política pública y dotar de mayor transparencia los actos de gobierno.

Si bien lo acontecido en las elecciones norteamericanas entusiasmaron e iluminaron a muchos políticos argentinos en tanto herramienta de campaña para incorporar a los ciudadanos a la promesa de cambio, los deseos de 'ser Obama' se vieron coartados por el adelantamiento de las elecciones legislativas cuatro meses antes de la fecha pautada. Ante el acortamiento de los tiempos, las estructuras partidarias se volcaron a las actividades de campaña tradicionales. No era el momento de innovar sin tener certezas del impacto que podrían tener dichas acciones, porque no había tiempo de revertirlos. Así fue como el Barómetro de Identidad Digital de eamericas. org demostró que menos del 30\% -de un total relevado de 60 candidatos de todas las listas a diputados nacionales por la Ciudad y Provincia de Buenos Aires- tenía una identidad propia construida en internet.

En la campaña legislativa de 2009 en Argentina se destaca el uso de la publicidad online por parte de la mayoría de los candidatos. Se utilizaron principalmente Google Ads tanto en su red de búsqueda como de contenidos. Hubo inversiones muy dispares, de entre $\$ 100.000$ pesos a $\$$ 1.000 por mes según el partido o candidato, con rendimientos también dispares muchas veces por la falta de una estrategia de comunicación clara de nuevos medios. El resto de los proyectos digitales no alcanzaron sus óptimos potenciales: portales con ausencia de contenidos exclusivos y escasa segmentación de mensajes; espacios en Facebook con muy bajo nivel de adherentes; nula fidelización del contacto a través del llamado a la acción de los posibles votantes e incapacidad de administrar el denominado buzz en las redes sociales.

Investigaciones anteriores del Observatorio Permanente muestran cómo esta aprehensión de los políticos argentinos a los nuevos medios durante la campaña no se sostiene una vez que 
llegan al gobierno. En 2008, solamente el 55\% de los legisladores porteños tenían una presencia online, en el distrito con mayor conectividad del país. Un estudio del mismo año reflejó que menos del $15 \%$ del total de municipios de Argentina un portal oficial en internet, siquiera como espacio mínimo de información del ciudadano.

Considerando las campañas políticas de 2009, Argentina se quedó claramente atrás en comparación a los países vecinos como Uruguay y Chile, cuyos candidatos a presidente se destacaron por el uso de aplicaciones de crowdsourcing similares a la red mybrackobama.com que no superó los 5.000 usuarios en ninguno de los casos. En el ranking de popularidad de Facebook, si se suman los seguidores de todos los líderes latinoamericanos y de los candidatos presidenciales de Argentina, el número resultante no alcanza al 10\% del total de seguidores de Barack Obama, que ya supera los 7 millones.

Los políticos argentinos están claramente en su fase 1.0 y todavía se está a la espera de escenas primarias 2.0 que marquen un antes y un después de la comunicación política de nuestro país. Seguramente las elecciones presidenciales del 2011 mostrarán un avance en este sentido, puesto que las experiencias previas en el país, y las de los países vecinos, hacen pensar que la tendencia irá en aumento, con una mayor comprensión del paradigma cuyos elementos se han tornado indispensables para la comunicación política.

\section{Bibliografía}

Anderson, C. (2007) La economía Long Tail. Barcelona: Ediciones Urano.

Battelle, J. (2006) Buscar. Barcelona: Ediciones Urano.

Castels, M. (1999) La era de la Información. Vol.1. México: Siglo XXI.

Jenkins, H. (2008). Convergence culture. Barcelona: Paidós Comunicación.

Johnson, S. (2003) Sistemas emergentes. Madrid: Turner.

Fidel, N. (2008). Barómetro de Identidad Política 2.0. 100 políticos Argentinos. Buenos Aires:

Eamericas.org

Mediosfera (s/f), disponible en http://mediosfera.wordpress.com/about/

Plouffe, D. (2009) The Audacity to Win. Washington: Viking.

Piscitelli, A. (2009). Nativos Digitales. Buenos Aires: Santillana.

Varios autores(2009). Cuaderno 28. Buenos Aires: Universidad de Palermo.

Winograd, M. y Hais, M. (2008) Millennial Makeover. USA: Rugter Press.

Smith, A. (2009) The Internet's Role in Campaign 2008. Washington: Pew Internet \& American Life Project.

Smith, A. y otros (2009) The Internet and Civic Engagement. Washington: Pew Internet and Civic Engagement.

Summary: This article analyzes how new media - like Internet and social networks have changed the ecosystem of political information, with new channels and information flowing with greater rapidity, with a consumer who is also generating of the news: the new prosumer. The convergence between traditional and new media, demand new mental capabilities on behalf of the users. And new skills on the part of the political candidates, who need to intervene with 
segmented messages and capacity to administer the conversation. Also, emblematic cases are analyzed, like Barack Obama's campaign as an icon of political communication 2.0, and different scenarios are described and contextualised, according to data of the Permanent Observatory of Politics 2.0 of the Institute of Politics \& Democracy of the Society of the Information for the Americas (eamericas.org).

Key words: 2.0 policy - Communication people - communications director - corporate communication - digital communication - government public - institutional communication - new technologies - organizational communication - Political communication - public - public policies - Public Relations - social media - social networks - strategic communication - Twitter.

Resumo: Este artigo analisa como os novos meios -como Internet e as redes sociais- hão trocado o eco sistema de informação política, com novos canais e informação fluindo com maior rapidez, com um consumidor que agora também é gerador de notícias: o novo prosumidor. Nesta convergência de meios tradicionais e novos, demanda novas capacidades cognitivas dos usuários. E novas destrezas por parte dos candidatos políticos, que precisam intervir com mensagens mais segmentadas e com capacidade para administrar a conversa. Também, analisam-se casos emblemáticos, como a campanha de Barack Aboma como ícono da comunicação política 2.0, e descrevem-se e contextualizam palcos e orçamentos, segundo dados do Observatório Permanente de Política 2.0, do Instituto Política \& Democracia da Sociedade da Informação para as Américas.

Palavras chave: comunicação digital - comunicação estratégica - Comunicação política - comunicadores - Dircom - novas tecnologias - política 2.0 - público governo - públicos - Relações Públicas - redes sociais - social media - Twitter.

$\left.{ }^{*}\right)$ Lucas Lanza. Estudió Ciencias de la Comunicación en la Universidad de Buenos Aires, realizó posgrados sobre gobernabilidad, gerencia política y desarrollo de comunidades locales en la Universidad San Andrés y en el IAE de la Universidad Austral. Becario del International Visitor Leadership Program (Gobierno de los EEUU). [Ver CV completo en la página 140]

Natalia Fidel. Licenciada en Ciencia Política (Universidad de San Andrés), con especialización en Administración y Políticas Públicas (LSE y Udesa). [Ver CV completo en la página 141] 